\title{
Impact of intra-operative cell salvage on blood coagulation in high-bleeding-risk patients undergoing cardiac surgery with cardiopulmonary bypass: a prospective randomized and controlled trial
}

\author{
Sheliang Shen ${ }^{1 * \dagger}$, Jun Zhang ${ }^{2 \dagger}$, Wenyuan Wang ${ }^{1}$, Jiayin Zheng ${ }^{3}$ and Yihong Xie ${ }^{4}$
}

\begin{abstract}
Background: Intra-operative cell salvage (CS) was reported to have no impairment on blood coagulation in lowbleeding-risk cardiac surgery with cardiopulmonary bypass (CPB), but studies in high-bleeding-risk cardiac surgery are limited. The objective of this study is to evaluate the impact of CS on blood coagulation in high-bleeding-risk cardiac surgery with CPB.

Methods: One hundred and ten patients were randomly assigned to either with intra-operative CS group (Group CS) or without intra-operative CS group (Group C). Study endpoints included the incidence of impairment of blood coagulation during perioperative period (peri-op) and the incidence of adverse events during postoperative period (post-op). Peri-op was defined as the period from beginning of anesthesia (anesthesia induction) to $24 \mathrm{~h}$ after end of surgery. Post-op was defined as the period from the end of surgery to $24 \mathrm{~h}$ after end of surgery. The types of impairment of blood coagulation included heparin residual, coagulopathy due to low PLT, coagulopathy due to low FIB, coagulopathy due to low coagulation factors, hyperfibrinolytic. The sum of above five types was total impairment of blood coagulation. Adverse events included excessive bleeding, resternotomy, etc.

Results: The incidence of heparin residual measured both at the end of surgery and during post-op were significantly higher in Group CS than in Group C (15.09 vs 4.00, 13.21 vs $2.00 \% ; p=0.024,0.010$, respectively). Similarly, the incidence of total impairment of blood coagulation at the end of surgery and during post-op were significantly higher in Group CS than in Group C (32.08 vs 18.00, 26.42 vs $12.00 \% ; p=0.043,0.040$, respectively). The incidence of excessive bleeding during post-op was $32.08 \%$ in Group CS compared with $16.00 \%$ in Group C ( $p=0.038$ ). Intriguingly, CS was associated with a significantly increase in the relative risk ratios for heparin residual and excessive bleeding ( $p=0.034,0.049$, respectively).
\end{abstract}

Conclusions: Intra-operative CS could impair blood coagulation in the scenario of high-risk-bleeding cardiac surgery with CPB.

Keywords: Cell salvage, Cardiac surgery, High-risk, Bleeding, Coagulation

\footnotetext{
*Correspondence: hz-ssl@163.com

'Sheliang Shen and Jun Zhang contributed equally to this work

1 Department of Anesthesiology, Zhejiang Provincial People's Hospital,

Hangzhou, Zhejiang, China

Full list of author information is available at the end of the article
} 


\section{Background}

Individuals who undergo cardiac surgery with cardiopulmonary bypass (CPB) are often exposed to impaired blood coagulation, both as a result of dysfunction of platelet (PLT) and circulatory system was primed of large volumes of fluid $[1,2]$. Blood coagulation would be theoretically further impaired when cell salvage (CS) was used in this kind of surgery due to its procedure of centrifugation and washing [3, 4]. However, previous literatures indicated that CS had no impairment on blood coagulation in low-bleeding-risk cardiac surgery with CPB $[5,6]$.

High- bleeding-risk cardiac surgery with $\mathrm{CPB}$ refers to those surgeries with high risk of bleeding due to patients' poor physical condition and long duration and complexity of the surgery $[3,7,8]$. Among 1.25 million patients undergoing cardiac surgery all over the world each year, a large proportion is with high-bleeding-risk [9].The volume of autologous blood transfusion was much larger in high-bleeding-risk cardiac surgeries with $\mathrm{CPB}$ than in low-bleeding-risk ones [9, 10]. Studies demonstrated that volume of autologous blood transfusion was associated with the severity of impairment of blood coagulation [11-13]. We hypothesized that CS could impair blood coagulation when it was used in high-bleeding-risk cardiac surgery.

To date, parameters related to blood coagulation include thromboelastography (TEG) parameters and other hematological parameters such as PLT and FIB. TEG was reported as one of the best indicators of blood coagulation in cardiac surgery with CPB [14-16]. Combination of the test of kaolin-activated sample and the test of heparinase-modified kaolin-activated sample was reported much better to detect heparin residues $[17,18]$.
Till now, limited studies existed evaluating the impact of CS on blood coagulation in high-bleeding-risk cardiac surgery with $\mathrm{CPB}$. The aim of this prospective randomized and controlled clinical trial was to fill this gap. The primary endpoint of this trial was the incidence of impairment of blood coagulation during perioperative period (peri-op), which was defined as the period from beginning of anesthesia (anesthesia induction) to $24 \mathrm{~h}$ after end of surgery (Fig. 1). The secondary endpoint was the incidence of adverse events during postoperative period (post-op), which was defined as the period from the end of surgery to $24 \mathrm{~h}$ after end of surgery (Fig. 1).

\section{Methods \\ Patients}

This study was approved by the Ethics Committee of the Zhejiang Provincial People's Hospital (RCT ID: ChiCTR-TRC-13003268). Patients were enrolled in the study after written informed consent was signed. Inclusion and exclusion criteria were shown in Table $1[3,7$, 8]. One hundred and ten eligible patients were randomly assigned into two groups according to a randomization list: cell salvage group (Group CS) and control group (Group C). Patients in Group CS were treated with intraoperative CS while those in Group C without.

\section{CPB}

Tranexamic Acid (AMCHA, $30 \mathrm{mg} / \mathrm{kg}$ ) was infused in all patients after anesthesia induction [9]. The CPB was performed using a HL20 heart-lung machine (MAQUET, Israel) with an OCTOPUS4 extracorporeal membrane oxygenation (Medtronic, USA). The volume of fluid primed was $1.8 \mathrm{~L}$, the main ingredient was ringer's lactate

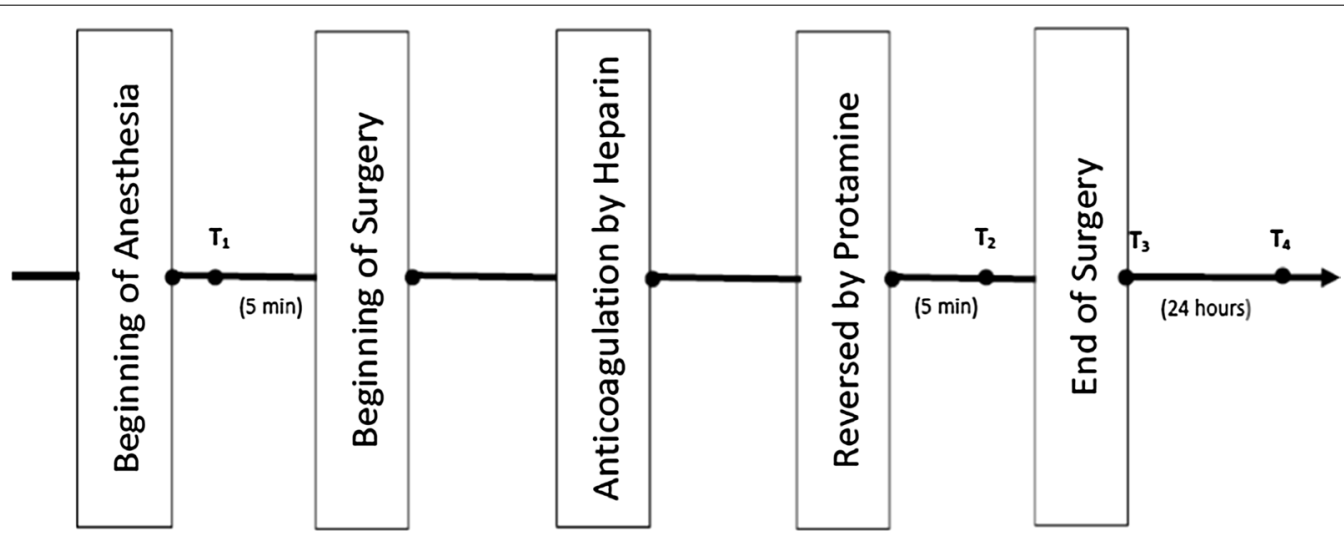

Fig. 1 The timeline of events. $T_{1} 5$ min before beginning of surgery, $T_{2} 5 \mathrm{~min}$ after heparin was reversed by protamine, $T_{3}$ at the end of surgery, $T_{4}$ at $24 \mathrm{~h}$ after end of surgery. Perioperative period (peri-op) the period from beginning of anesthesia to $24 \mathrm{~h}$ after end of surgery. Postoperative period (post-op) the period from the end of surgery to $24 \mathrm{~h}$ after end of surgery. The period of heparinization: the period from blood anticoagulated by heparin to heparin were reversed by protamine. The period of non-heparinization: the period from beginning of surgery to blood anticoagulated by heparin + the period from heparin were reversed by protamine to end of surgery 
Table 1 Inclusion and exclusion criteria of patients

\begin{tabular}{|c|c|c|}
\hline & Inclusion criteria & Exclusion criteria \\
\hline $\begin{array}{l}\text { Opportunity of } \\
\text { surgery }\end{array}$ & $\begin{array}{l}\text { Scheduled for cardiac } \\
\text { surgery with CPB }\end{array}$ & $\begin{array}{r}\text { Emergency cardiac } \\
\text { surgery with CPB }\end{array}$ \\
\hline \multirow[t]{3}{*}{ Type of surgery } & $\begin{array}{l}\text { Multiple valves } \\
\text { replacement }\end{array}$ & $\begin{array}{l}\text { The first time single } \\
\text { valve replacement }\end{array}$ \\
\hline & Bentall & \\
\hline & $\begin{array}{l}\text { Reoperation (at least } 1 \\
\text { item above } 3 \text { items } \\
\text { must be met) }\end{array}$ & \\
\hline \multirow{8}{*}{$\begin{array}{l}\text { Characteristics of } \\
\text { patient }\end{array}$} & Age $>70$ years & \\
\hline & $\mathrm{BSA}<1.6 \mathrm{~m}^{2}$ & \\
\hline & $\mathrm{Cr}>15 \mathrm{mg} / \mathrm{L}$ & \\
\hline & $\begin{array}{l}\text { Liver Child-Pugh B } \\
\text { or C }\end{array}$ & \\
\hline & $\mathrm{R}(\mathrm{TEG})>10 \mathrm{~min} ;$ & \\
\hline & $\begin{array}{l}\mathrm{HB}<13 \mathrm{~g} / \mathrm{dL} \text { (male) or } \\
12 \mathrm{~g} / \mathrm{dL} \text { (female) }\end{array}$ & \\
\hline & $\mathrm{PLT}<50 \times 10^{9} / \mathrm{L}$ & \\
\hline & $\begin{array}{l}\text { Drug with- } \\
\text { drawal }<3 \text { days } \\
\text { (Aspirin) or } 7 \text { days } \\
\text { (Clopidogrel) } \\
\text { (at least } 2 \text { items } \\
\text { above } 8 \text { items must } \\
\text { be met) }\end{array}$ & \\
\hline
\end{tabular}

Eligible patient must meet opportunity of surgery and type of surgery and characteristics of patient at the same time

Multiple valves replacement aortic valves replacement + mitral valve replacement

Bentall aortic valve replacement + ascending aorta and aortic root replacement Reoperation not the first time single or multiple valve replacement $B S A$ body surface area, TEG thromboelastography, HB hemoglobin, PLT platelets, Cr creatinine

solution, along with a small amount of albumin and mannitol. Anticoagulation was achieved with heparin to maintain an activated clotting time (ACT) above $480 \mathrm{~s}$. After separation from $\mathrm{CPB}$, heparin was reversed by protamine to a target-ACT of range from 90 to $110 \%$ of base value.

\section{Autologous blood transfusion}

In Group CS, shed blood from wound and mediastina were sucked into the cell saver reservoir (Haemonetics, USA, volume of disposable centrifuge bowl is $125 \mathrm{~mL}$ ) after anticoagulated by heparin saline during the period of non-heparinization (Fig. 1). The heparinised saline contain $25,000 \mathrm{IU}$ of heparin in $1 \mathrm{~L}$ of $0.9 \%$ saline at a rate of $100 \mathrm{~mL} / \mathrm{h}$. At the end of $\mathrm{CPB}$, residual blood in the $\mathrm{CPB}$ circuit was directly sucked into the reservoir. After being filtrated, centrifugated, washed and concentrated, the recovered blood turned into autologous blood (autologous red blood cell suspension), which was transfused back to the patient immediately. The washing program used in the CS involved a 5:1 ratio between the $0.9 \%$ saline wash and collection of blood from the operating field. All of the autologous blood was transfused back to the patients by the end of surgery. In Group C, shed blood from wound and mediastina during the period of non-heparinization (Fig. 1) were sucked into suction apparatus and were discarded. In Group $\mathrm{C}$, at the end of $\mathrm{CPB}$ residual blood in the $\mathrm{CPB}$ circuit were sucked into suction apparatus and were discarded. Patients' bleeding during the period of heparinization (Fig. 1) in two groups were sucked into the $\mathrm{CPB}$ circuit.

\section{Blood transfusion during peri-op}

After heparin was reversed by protamine, allogeneic red blood cell (RBC) was used if hemoglobin (HB) was lower than $8 \mathrm{~g} / \mathrm{dL}$ in Group C [3]. In Group CS, allogeneic RBC was used only if $\mathrm{HB}$ was still lower than $8 \mathrm{~g} / \mathrm{dL}$ after transfused all of the autologous blood. Allogeneic fresh-frozen plasma (FFP) and PLT transfusion was used during peri-op according to the protocol (showed in the seventh and eighth line in Fig. 2 [3, 16, 19]. Patients with excessive bleeding during post-op, which was defined as the rate of bleeding greater than $300 \mathrm{~mL}$ in the first hour after surgery or greater than $2 \mathrm{~mL} / \mathrm{kg} / \mathrm{h}$ for 3 consecutive hours, were treated according to the same protocol (Fig. 2).

\section{Study variables}

Basal and operative characteristics: including age, gender, BSA, type of surgery, complications, CPB time, surgical time, tracheal intubation time, length of ICU stay, length of hospital stay, the volume of residual blood in CPB circuit, the volume of intra-operative blood loss, the volume of mediastina tube drainage (MTD) in 6 and $24 \mathrm{~h}$ after surgery, intra-operative dosage of heparin and protamine. The volume of intra-operative blood loss was calculated as the volume sucked into cell saver reservoir minus the volume of heparin saline for anticoagulation in Group CS or the volume sucked into suction apparatus in Group C.

Volume of blood transfusion during peri-op: including the volume of autogenous blood in Group CS, the volume of allogeneic blood (RBC, PLT and FFP) in two groups.

Hematological parameters during peri-op: including general parameters and parameters related to blood coagulation. General parameters included RBC and HB. Parameters related to blood coagulation included TEG parameters (Haemonetics, USA), PLT and FIB. TEG parameters included $\mathrm{R}$ value (R-TEG and R-h-TEG), MA and LY 30. R (reaction time, normal range from 10 to $19 \mathrm{~min}$ ) represents the time to initiation of clot formation. R-TEG and R-h-TEG are the R value of test of kaolin-activated sample and heparinase-modified kaolin-activated sample, respectively; MA (maximum amplitude, normal range from 54.5 to $72.5 \mathrm{~mm}$ ) represents the maximum 


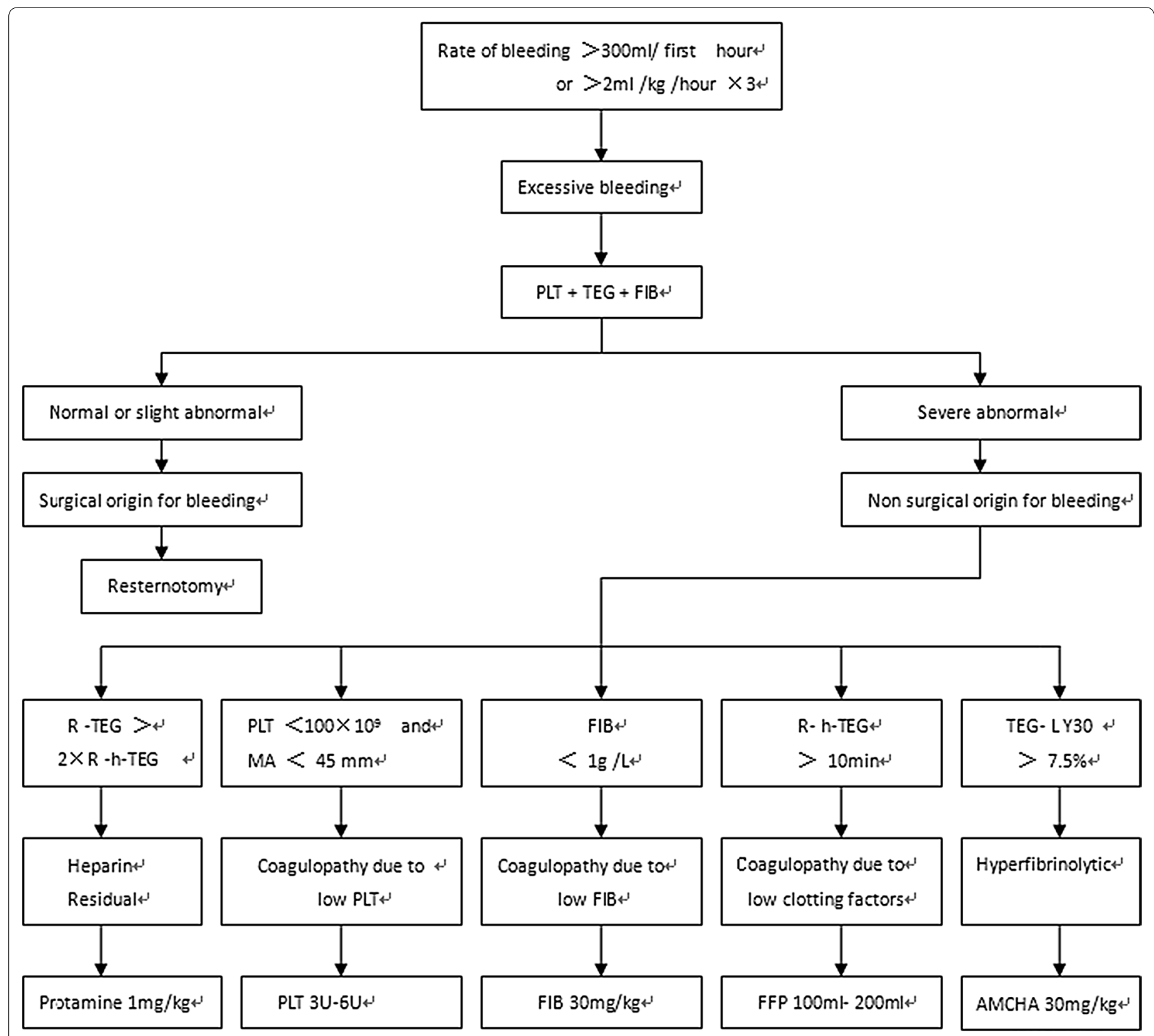

Fig. 2 The processing protocol of excessive bleeding during post-op. Once excessive bleeding was diagnosed, patients received treatment based on the results of the tests in the TEG, PLT and FIB. First hour: in the first hour after surgery, hour $\times 3$ : for 3 consecutive hours. TEG kaolin-activated TEG, $h$-TEG heparinase-modified kaolin-activated TEG, $R$ reaction time, $R$-TEG $R$ value in TEG, $R$ - $h$-TEG $R$ value in $h$-TEG, MA maximum amplitude, LY30 lysis index at $30 \mathrm{~min}$, PLT platelets, FFP fresh-frozen plasma, FIB fibrinogen, AMCHA tranexamic acid

clot strength; LY30 (lysis rate-30, normal range from 0 to $7.5 \%)$ represents the rate of cloth lysis $30 \mathrm{~min}$ after MA. Venous blood was tested at the following four time points or anytime when excessive bleeding occurred during postop: at the time of after anesthesia induction and $5 \mathrm{~min}$ before beginning of surgery $\left(\mathrm{T}_{1}\right), 5$ min after heparin was reversed by protamine during surgery $\left(\mathrm{T}_{2}\right)$, at the end of surgery $\left(\mathrm{T}_{3}\right)$ and at $24 \mathrm{~h}$ after end of surgery $\left(\mathrm{T}_{4}\right)$ (Fig. 1$)$.

Impairment of blood coagulation during peri-op: impairment of blood coagulation was diagnosed according to the test results of hematological parameters related to blood coagulation (showed in the seventh and eighth line in Fig. 2). Impairment of blood coagulation were classified into five types: heparin residual, coagulopathy due to low PLT (decreasing of PLT results in hypocoagulability), coagulopathy due to low FIB (shortage of FIB results in hypocoagulability), coagulopathy due to low coagulation factors (shortage of other coagulation factors except for factor results in hypocoagulability) and hyperfibrinolytic (showed in the seventh and eighth line in Fig. 2) $[17,19]$. The sum of above five types was total impairment of blood coagulation. 
Adverse events during post-op: including excessive bleeding, resternotomy, cardiovascular failure, severe arrhythmias, myocardial infarction, infection, renal failure, respiratory failure, epileptic syndrome, cognitive decline and death.

\section{Statistical analysis}

Data are presented as mean (standard deviation, SD) for continuous parametric values, or as numbers with percentage for categorical data. For continuous data, the two-sample two-sided Student's t test or the Wilcoxon Rank-Sum two-sample two-sided test was used. For categorical data, the $\chi^{2}$ test or Fisher's exact-test was used. Considering some variables may influence relevant clinical outcomes potentially, the logistic regression model was used to analyze the outcomes in Table 4. Odds ratios (ORs) resulting from logistic regression analysis were used to estimate relative risk (RR) ratios. Data analysis was performed using SAS statistical software (version 9.1; SAS Institute Inc., Cary, NC, USA). $P$ value of less than 0.05 was considered as statistically significant.

\section{Results}

\section{Basal and operative characteristics}

Of the total 110 patients randomized between April 2013 and September 2014, 55 were allocated to Group CS and 55 to Group C (Fig. 3). There was no difference between two groups in the listed variables (Table 2).

\section{Blood transfusion during peri-op}

The mean volume of autologous blood transfusion in Group CS was $4.13 \mathrm{U}(0.31 \mathrm{U})$. The proportion of allogeneic RBC transfusion during peri-op was $41.51 \%$ in Group CS versus 78.00 \% in Group C. The mean volume of allogeneic RBC transfusion during peri-op was $2.66 \mathrm{U}$ in Group CS versus 5.40 U in Group C. Both the proportion and volume of allogeneic $\mathrm{RBC}$ transfusion during peri-op were significantly lower in Group CS than in Group C (Table 3).

\section{Impairment of blood coagulation during peri-op}

The incidences of heparin residual at $\mathrm{T}_{3}$ and during post-op were significant higher in Group CS (15.09 and $13.21 \%)$ than in Group C (4.00 and $2.00 \%)$, with $p$ value as 0.024 and 0.010 , respectively (Fig. 4 ). Similarly, the incidences of total impairment of blood coagulation at $T_{3}$ and during post-op were significant higher in Group CS (32.08 and $26.42 \%$ ) than in Group C (18.00 and $12.00 \%)$, with $p$ value as 0.043 and 0.040 , respectively (Fig. 4). The $R R$ value of CS with heparin residual was 6.10. CS was associated with an increase in the RR for heparin residual $(p=0.034)$ (Table 5).

\section{Adverse events during post-op}

The incidence of excessive bleeding during post-op were significantly higher in Group CS (32.08 \%) than in Group C $(16.00 \%)$ (Table 4). The RR value of CS with excessive bleeding was 4.58. CS was associated with an increase in the RR for excessive bleeding $(p=0.049)$ (Table 5).

\section{Discussion}

In our present study, significant differences of the incidence of heparin residues and total impairment of blood coagulation during peri-op were found between two groups. We also found that the incidence of excessive bleeding during post-op was significantly higher in group CS than in group C. In addition, we found that CS was a dependent risk factor for heparin residues and excessive bleeding. These results indicate that intra-operative CS could impair blood coagulation in the scenario of highrisk-bleeding cardiac surgery with $\mathrm{CPB}$, which is consistent with our hypothesis.

$\mathrm{CPB}$ determines an activation of the coagulation system $[1,2]$. CS system determines a further activation of the coagulation system $[3,4,20]$. The enhanced activation of the coagulation system induced a strong thrombin generation. Thrombin generation directly consumes coagulation factors, activates PLT, promotes fibrinolysis, lowers fibrinolysis inhibition and stimulates the release of tissue plasminogen activator from endothelial cells [20]. These conditions were considered as a possible trigger for a consumption coagulopathy and hyperfibrinolysis.

In our practice, processing of recovered blood during the CS process involves the collection of blood and mixing with heparinised saline, centrifugation of the cells, followed by saline washing prior to re-transfusion to the patient. The washing program used in the CS involved a $5: 1$ ratio between the $0.9 \%$ saline wash and collection of blood. This process removes plasma proteins and coagulation factors. In addition, hemodilution during $\mathrm{CPB}$ and the fluid therapy during post-CPB may result in dilutional coagulopathy $[12,21]$.

To prevent thrombogenesis during the collection of blood, as the standard protocol practiced in our study, the heparinised saline containing 25,000 IU of heparin in $1 \mathrm{~L}$ of $0.9 \%$ saline at a rate of $100 \mathrm{~mL} / \mathrm{h}$ was used. Previous studies revealed that after the recovered blood processed by the CS system. The autologous blood may contain heparin about 500 IU/L [12]. In our study, the incidence of heparin residual at the end of surgery were 15.09 \% in Group CS and 4 \% in Group C, respectively. This result reveals that residual heparin from the CS system could worsen the coagulopathy and also is an important trigger for the impairment of blood coagulation in these patients. 


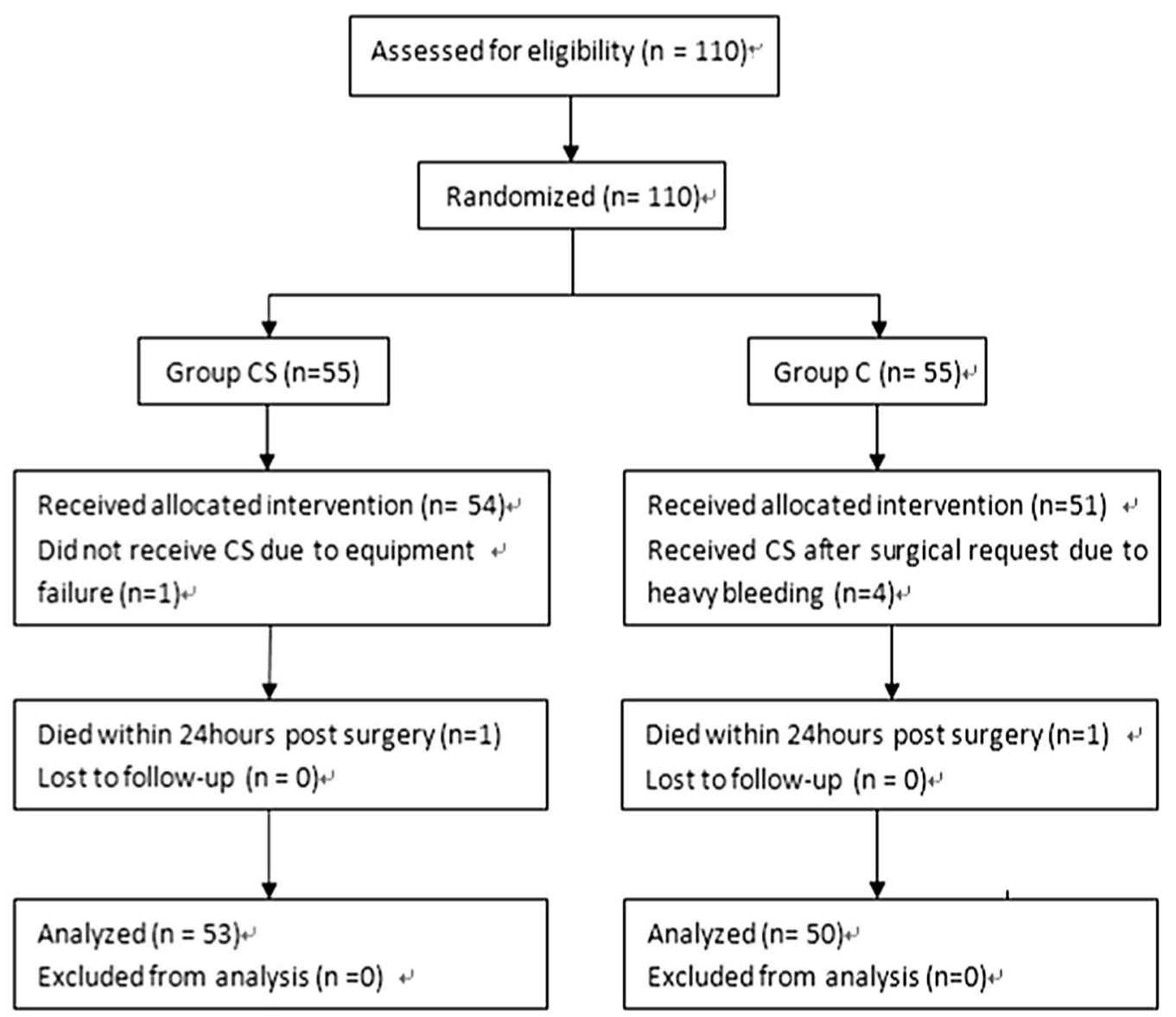

Fig. 3 CONSORT diagram of flow of patients

The dose of heparin in the autologous blood that was transfused back to the patient could vary depends on the transfusion volume, concentration and drip rate of heparinised saline. We found it is very cumbersome in clinical practice to estimate the level of heparin in the autologous blood. Anticoagulation was commonly monitored with ACT. Clinicians would have to use protamine to reverse the residual heparin according to the ACT value. The value of ACT may be prolonged by hemodilution which is very common in this kind of surgery [22]. Thus, ACT is a partially reliable bedside method for monitoring the adequacy of anticoagulation. Recent studies revealed that the TEG is a more reliable and sensitive method for assessment of the heparinization level after the autologous blood transfusion [16, 23]. In our study, the $R$ values of heparinase-modified kaolin-activated samples (R-h-TEG) were compared with those of kaolinactivated samples (R-TEG) to assess heparin residual.

The appropriate concentration of the anticoagulant heparin saline and the degree of washing performed by the CS are vital to preventing the heparin residual from the autologous blood. The concentration of the anticoagulant heparin saline used was 50,000 IU/L, even $30,000 \mathrm{IU} / \mathrm{L}$ in some report [24]. In our study, although the concentration 25,000 IU/L and the degree of washing $5: 1$ volume ratio between the $0.9 \%$ saline wash and blood were used, the incidence of heparin residual at the end of surgery in Group CS was up to $15.09 \%$. This implies that the concentration of $25,000 \mathrm{IU} / \mathrm{L}$ may be still risky [22]. The solution to this specific problem may be either reducing the concentration of anticoagulant heparin saline or administering an appropriate dose of protamine to reverse heparin depends on the monitoring of TEG. However, reducing the concentration of heparin may result in thrombogenesis during the collection of blood from the operating field. On the other hand, increasing the dose of protamine may cause adverse events such as allergic reactions. Future studies with a large sample size are urgently begged to further evaluate the appropriate concentration of the anticoagulant heparin saline.

Literatures indicated that intra-operative CS has no impairment on blood coagulation in low-bleeding-risk 
Table 2 Patients' basal and operative characteristics

\begin{tabular}{|c|c|c|c|}
\hline Variable & Group CS $(n=53)$ & Group C $(n=50)$ & $P$ value \\
\hline Age (years) & $50.42(15.43)$ & $52.53(15.65)$ & 0.549 \\
\hline$>70$ & $12(22.64)$ & $13(26.00)$ & 0.691 \\
\hline Male & $27(50.94)$ & $24(48.00)$ & 0.765 \\
\hline BSA & $1.73(0.14)$ & $1.73(0.13)$ & 0.946 \\
\hline$<1.6 \mathrm{~m}^{2}$ & $5(9.43)$ & $4(8.00)$ & 1.000 \\
\hline Surgery type & & & 0.922 \\
\hline Multiple valve & $36(67.92)$ & $33(66.00)$ & \\
\hline Bentall & $8(15.09)$ & $7(20.00)$ & \\
\hline Reoperations & $9(16.98)$ & $10(14.00)$ & \\
\hline \multicolumn{4}{|l|}{ Preoperative complication } \\
\hline Renal dysfunction & $19(35.84)$ & $18(36.00)$ & 0.987 \\
\hline Liver insufficiency & $9(16.98)$ & $7(14.00)$ & 0.676 \\
\hline Coagulation disorders & $15(28.30)$ & $13(26.00)$ & 0.793 \\
\hline \multirow[t]{2}{*}{ HB levels lower ( $<13 \mathrm{~g} / \mathrm{dL}$ in male or $<12 \mathrm{~g} / \mathrm{dL}$ in female) } & $21(39.62)$ & $23(46.00)$ & 0.513 \\
\hline & $17(32.08)$ & $18(36.00)$ & 0.674 \\
\hline PLT levels lower $\left(<50 \times 10^{9} / \mathrm{L}\right)$ intake of aspirin or clopidogrel & $12(22.53)$ & $11(22.00)$ & 0.938 \\
\hline CPB time (min) & $136.05(36.82)$ & $126.65(25.63)$ & 0.342 \\
\hline Surgical time (min) & $302.56(28.02)$ & $295.94(22.02)$ & 0.220 \\
\hline Tracheal intubation time (hour) & $13.92(10.83)$ & $13.15(3.62)$ & 0.434 \\
\hline Length of ICU stay (hour) & $19.42(4.43)$ & $20.42(4.16)$ & 0.099 \\
\hline Length of hospital stay (day) & $22.56(4.23)$ & $23.38(4.54)$ & 0.206 \\
\hline Residual blood in CPB circuit & $853.67(50.46)$ & $837.22(92.53)$ & 0.200 \\
\hline Intra-operative blood loss (mL) & $1640.96(87.73)$ & $1609.03(137.91)$ & 0.072 \\
\hline \multicolumn{4}{|l|}{$\operatorname{MTD}(\mathrm{mL})$} \\
\hline $\ln 6 \mathrm{~h}$ & $333.02(147.14)$ & $295.03(152.82)$ & 0.301 \\
\hline $\ln 24 \mathrm{~h}$ & $657.78(272.94)$ & $591.96(171.53)$ & 0.071 \\
\hline Intra-operative heparin dose (mg) & $244.63(49.82)$ & $241.06(49.35)$ & 0.778 \\
\hline Intra-operative protamine dose (mg) & $428.37(92.83)$ & $417.36(92.02)$ & 0.478 \\
\hline
\end{tabular}

Data are presented as mean (SD) or number (percentage)

MTD mediastinal tube drainage, patients with resternotomy were not calculated

Table 3 Allogeneic blood transfusion during peri-op

\begin{tabular}{lllr}
\hline Variable & Group CS $(\mathbf{n = 5 3 )}$ & Group C $(\mathbf{n}=\mathbf{5 0 )}$ & P value \\
\hline RBC & & & \\
Proportion & $22(41.51)$ & $39(78.00)$ & 0.0002 \\
Volume $(U)$ & $2.11(2.66)$ & $5.40(3.48)$ & $<0.0001$ \\
FFP & & & \\
Proportion & $10(18.87)$ & $9(18.00)$ & 0.910 \\
Volume $(\mathrm{mL})$ & $118.76(253.82)$ & $129.00(284.92)$ & 0.953 \\
PLT & & & \\
Proportion & $12(22.64)$ & $10(20.00)$ & 0.744 \\
Volume $(U)$ & $1.81(3.56)$ & $1.92(3.94)$ & 0.916 \\
\hline
\end{tabular}

Data are presented as mean (SD) or number (percentage)

cardiac surgery with $\mathrm{CPB}[5,6]$. In our present study, intra-operative CS could impair blood coagulation in the scenario of high-risk-bleeding cardiac surgery with $\mathrm{CPB}$.
Previous studies reported that the volume of autologous blood transfused back to the patient in high-bleedingrisk cardiac surgery with $\mathrm{CPB}$ was much larger than in low-bleeding-risk cardiac surgery $[9,10]$. All types of impairment of blood coagulation are associated with the volume of autologous blood. The more autologous blood transfused, the more severe the impairment of CS on blood coagulation to be expected.

To the best of our knowledge, our study is the first prospective randomized controlled clinical trial investigating the impact of CS on blood coagulation in high-risk-bleeding cardiac surgery with $\mathrm{CPB}$. As the increasing popularity of the CS, more attention should be focused on the patients' blood coagulation after the autologous blood transfusion, especially in the patients in high-bleedingrisk cardiac surgery with $\mathrm{CPB}$. This study highlighted the importance of the blood coagulation monitoring which could be overlooked in these situations [24]. We strongly 


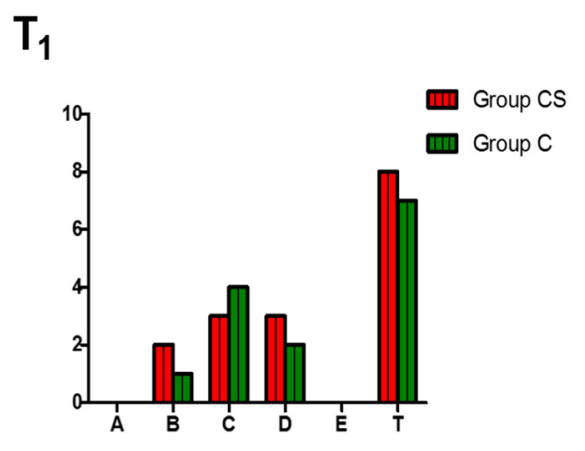

\section{$\mathrm{T}_{2}$}

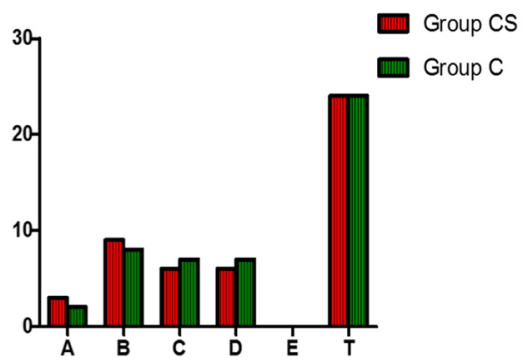

$\mathrm{T}_{3}$

Post-op

$\mathrm{T}_{4}$

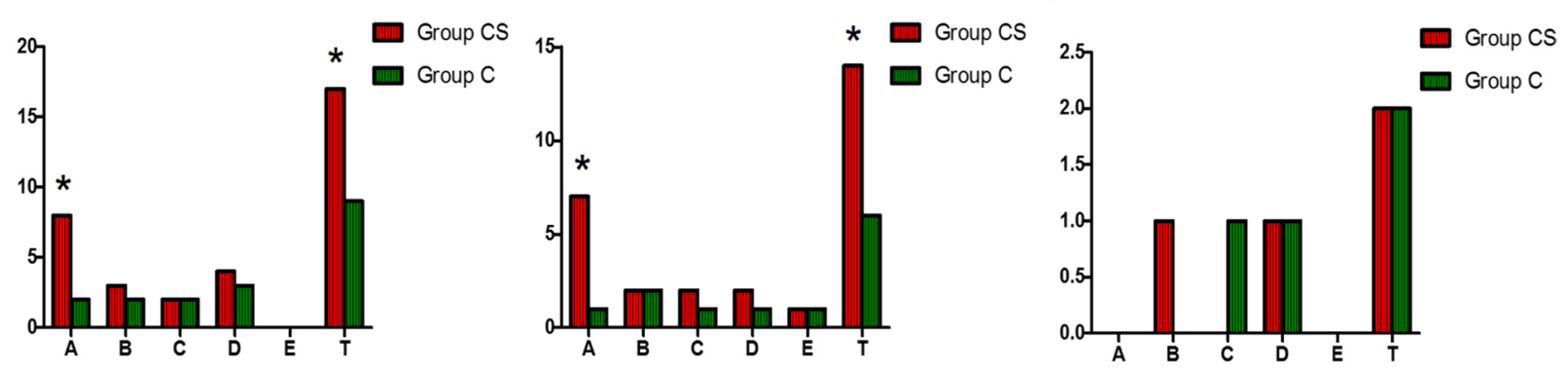

Fig. 4 Comparison of impairment of blood coagulation during peri-op between two groups. $x$-axis type of impairment of blood coagulation, $A$ heparin residual, $B$ coagulopathy for low PLT, C coagulopathy for low FIB, D coagulopathy for low clotting factors, $E$ hyperfibrinolysis, $T$ total $(A+B+C+D+E)$. $y$-axis cases of each type, $T_{1}$ at the time of after anesthesia induction and 5 min before surgery, $T_{2} 5$ min after heparin was reversed by protamine during surgery, $T_{3}$ at the end of surgery, post-op during postoperative period, $T_{4}$ at the time of $24 \mathrm{~h}$ after surgery. ${ }^{*} p=0.024\left(T_{3}-A\right), 0.043\left(T_{3}-T\right), 0.010($ post-op $-A), 0.040$ (post-op $-T$ ), respectively

Table 4 Relationship of CS with impairment of blood coagulation and adverse events

\begin{tabular}{lcll}
\hline Variable & RR & $\mathbf{9 5} \% \mathbf{C l}$ & P value \\
\hline Heparin residual & 6.10 & $1.14-32.60$ & 0.034 \\
Coagulopathy for low PLT & 0.61 & $0.14-2.61$ & 0.509 \\
Coagulopathy for low FIB & 1.35 & $0.40-4.48$ & 0.629 \\
$\begin{array}{l}\text { Coagulopathy for low clotting } \\
\text { factors }\end{array}$ & 0.56 & $0.09-3.30$ & 0.521 \\
Excessive bleeding & 4.58 & $1.02-18.34$ & 0.049 \\
Myocardial infarction & 0.15 & $0.01-1.99$ & 0.150 \\
Cognitive decline & $<0.001$ & $<0.001-999.99$ & 0.938 \\
\hline
\end{tabular}

$R R$ relative risk, $\mathrm{Cl}$ confidence interval

recommend application of monitoring of blood coagulation by the TEG combined with kaolin-activated sample and heparinase-modified kaolin-activated sample. Our experience was valuable for anesthesiologists and surgeons to deal with the impairment of blood coagulation in this kind of surgery.

One limitation of our study was the evaluation standard of high-bleeding-risk cardiac surgery. Because there
Table 5 Summary of adverse events during post-op

\begin{tabular}{llll}
\hline Variable & Group CS (n= 53) & Group C (n= 50) & P value \\
\hline Excessive bleeding & $17(32.08)$ & $8(16.00)$ & 0.038 \\
Resternotomy & $3(5.66)$ & $2(4.00)$ & 1.000 \\
Cardiovascular failure & $6(11.32)$ & $7(14.00)$ & 0.682 \\
Severe arrhythmias & $4(7.55)$ & $3(6.00)$ & 1.000 \\
$\quad$ requiring treatment & & & \\
Myocardial infarction & $1(1.89)$ & $4(8.00)$ & 0.196 \\
Infection & $7(13.21)$ & $6(12.00)$ & 0.948 \\
Wound & $3(5.66)$ & $2(4.00)$ & 1.000 \\
$\quad$ Others & $4(7.55)$ & $4(8.00)$ & 1.000 \\
Renal failure & $5(9.43)$ & $4(8.00)$ & 1.000 \\
Respiratory failure & $3(5.66)$ & $2(4.00)$ & 1.000 \\
Epileptic syndrome & $1(1.89)$ & $1(2.00)$ & 1.000 \\
Cognitive decline & $0(0.00)$ & $3(6.00)$ & 0.111 \\
Death & $0(0.00)$ & $0(0.00)$ & \\
\hline Data are presented as & & &
\end{tabular}

Data are presented as number (percentage)

is no universal standard so far, the standard we employed may need some modification. In addition, double blind research method was not adopted in the present study 
due to objective reasons, which may include some bias. This protocol may affect our results. Another limitation of present study was the administration of AMCHA which lowers fibrinolysis. Accordingly, the incidence of hyperfibrinolysis in two groups were lower than usual.

\section{Conclusion}

Our preliminary data support a proposal that intra-operative CS could impair blood coagulation in the scenario of high-risk-bleeding cardiac surgery with $\mathrm{CPB}$.

\begin{abstract}
Abbreviations
CS: cell salvage; CPB: cardiopulmonary bypass; Peri-op: perioperative period, the period from anesthesia induction to $24 \mathrm{~h}$ after surgery; Post-op: postoperative period, the period from the end of surgery to $24 \mathrm{~h}$ after surgery; TEG: thromboelastography, kaolin-activated TEG; $h$-TEG: heparinase-modified kaolin-activated TEG; R: reaction time; R-TEG: $R$ value in TEG; $R-h-T E G$ : $R$ value in h-TEG; MA: maximum amplitude; LY30: Iysis index at 30 min; AMCHA: tranexamic acid; ACT: activated clotting time; RBC: red blood cell; HB: hemoglobin; PLT: platelets; FIB: fibrinogen; FFP: fresh-frozen plasma; MTD: the volume of mediastina tube drainage; RR: relative risk.
\end{abstract}

\section{Authors' contributions}

SS conceived the study, coordinated the group and prepared the manuscript. $Y X$ is responsible for conception and design, acquisition of data and critical revision of the manuscript for important intellectual content. JZ and WW are responsible for interpretation of data and drafting the manuscript. JZ is responsible for statistical analysis. All authors read and approved the final manuscript.

\section{Author details}

${ }^{1}$ Department of Anesthesiology, Zhejiang Provincial People's Hospital, Hangzhou, Zhejiang, China. ${ }^{2}$ Department of Orthopedics, Zhejiang Provincial People's Hospital, Hangzhou, Zhejiang, China. ${ }^{3}$ Department of Probability and Statistics, School of Mathematical Sciences, Beijing University, Beijing, China. ${ }^{4}$ Department of Cardiothoracic Surgery, Zhejiang Provincial People's Hospital, Hangzhou, Zhejiang, China.

\section{Competing interests}

The authors declared that they have no competing interests.

\section{Ethics, consent and permissions}

This study was approved by the Ethics Committee of the Zhejiang Provincial People's Hospital (Approval document ID: 2013KY035).

\section{Funding}

Natural Science Foundation of Zhejiang Province provided financial support for the design of this study, as well as collection, analysis and interpretation of data. The approval document ID was LY12H08005.

Received: 3 March 2016 Accepted: 20 July 2016

Published online: 29 July 2016

\section{References}

1. Sniecinski RM, Chandler WL. Activation of the hemostatic system during cardiopulmonary bypass. Anesth Analg. 2011;113(6):1319-33.

2. Romlin BS, Wåhlander H, Synnergren M, Baghaei F, Jeppsson A. Earlier detection of coagulopathy with thromboelastometry during pediatric cardiac surgery: a prospective observational study. Paediatr Anaesth. 2013;23(3):222-7.

3. Klein AA, Nashef SA, Sharples L, Bottrill F, Dyer M, Armstrong J, Vuylsteke A. A randomized controlled trial of cell salvage in routine cardiac surgery. Anesth Analg. 2008;107(5):1487-95.
4. Ashworth A, Klein AA. Cell salvage as part of a blood conservation strategy in anaesthesia. Br J Anaesth. 2010;105(4):401-16.

5. Niranjan G, Asimakopoulos G, Karagounis A, Cockerill G, Thompson M, Chandrasekaran V. Effects of cell saver autologous blood transfusion on blood loss and homologous blood transfusion requirements in patients undergoing cardiac surgery on-versus off-cardiopulmonary bypass: a randomised trial. Eur J Cardiothorac Surg. 2006;30(2):271-7.

6. Golab HD, Scohy TV, de Jong PL, Takkenberg JJ, Bogers AJ. Intraoperative cell salvage in infants undergoing elective cardiac surgery: a prospective trial. Eur J Cardiothorac Surg. 2008;34(2):354-9.

7. Reyes G, Prieto M, Alvarez P, Orts M, Bustamante J, Santos G, Sarraj A, Planas A. Cell saving systems do not reduce the need of transfusion in low-risk patients undergoing cardiac surgery. Interact CardioVasc Thorac Surg. 2011;12(2):189-93.

8. Ferraris VA, Ferraris SP, Saha SP, Hessel EA 2nd, Haan CK, Royston BD, Bridges CR, Higgins RS, Despotis G, Brown JR. Society of cardiovascular anesthesiologists special task force on blood transfusion, Spiess BD, Shore-Lesserson L, Stafford-Smith M, Mazer CD, Bennett-Guerrero E, Hill SE, Body S: Perioperative blood transfusion and blood conservation in cardiac surgery: the Society Of Thoracic Surgeons and the Society Of Cardiovascular Anesthesiologists clinical practice guideline. Ann Thorac Surg. 2007;83(5):S27-86.

9. Fergusson DA, Hébert PC, Mazer CD, Fremes S, MacAdams C, Murkin JM, Teoh K, Duke PC, Arellano R, Blajchman MA, Bussières JS, Côté D, Karski J, Martineau R, Robblee JA, Rodger M, Wells G, Clinch J. Pretorius R; BART Investigators. A comparison of aprotinin and lysine analogues in high-risk cardiac surgery. N Engl J Med. 2008;358(22):2319-31.

10. Karkouti K, Beattie WS, Dattilo KM, McCluskey SA, Ghannam M, Hamdy A, Wijeysundera DN, Fedorko L, Yau TM. A propensity score case-control comparison of aprotinin and tranexamic acid in high-transfusion-risk cardiac surgery. Transfusion. 2006;46(3):327-38.

11. Campbell J, Holland C, Richens D, Skinner H. Impact of cell salvage during cardiac surgery on the thrombelastomeric coagulation profile: a pilot study. Perfusion. 2012;27(3):221-4.

12. Rollins KE, Trim NL, Luddington RJ, Colah S, Klein A, Besser MW, Nair SK. Coagulopathy associated with massive cell salvage transfusion following aortic surgery. Perfusion. 2012;27(1):30-3.

13. Rudra P, Basak S. Coagulopathy during intraoperative cell salvage in a patient with major obstetric haemorrhage. Br J Anaesth. 2011;106(2):280-1.

14. De Somer F. Understanding the delicate balance between bleeding and thrombosis: can we use it to our advantage? J Extra Corpor Technol. 2012;44(1):13-5.

15. Spahn DR, Ganter MT. Towards early individual goal-directed coagulation management in trauma patients. Br J Anaesth. 2010;105(2):103-5.

16. Ak K, Isbir CS, Tetik S, Atalan N, Tekeli A, Aljodi M, Civelek A, Arsan S. Thromboelastography-based transfusion algorithm reduces blood product use after elective CABG: a prospective randomized study. J Card Surg. 2009;24(4):404-10.

17. Ji HW, Ma L, Gao XR. Application of thromboelastography in cardiovascular surgery. Chin J ECC. 2011;9(3):170-2.

18. Zmuda K, Neofotistos D, Ts'ao CH. Effects of unfractionated heparin, low-molecular-weight heparin, and heparinoid on thromboelastographic assay of blood coagulation. Am J Clin Pathol. 2000;113(5):725-31.

19. Diprose P, Herbertson MJ, O'Shaughnessy D, Deakin CD, Gill RS. Reducing allogeneic transfusion in cardiac surgery: a randomized double-blind placebo-controlled trial of antifibrinolytic therapies used in addition to intra-operative cell salvage. Br J Anaesth. 2005;94(3):2718.

20. Paparella D, Whitlock R. Safety of salvaged blood and risk of coagulopathy in cardiac surgery. Semin Thromb Hemost. 2016;42(2):166-71.

21. Scrascia G, Rotunno C, Nanna D, Rociola R, Guida P, Rubino G, de Luca Tupputi Schinosa L, Paparella D. Pump blood processing, salvage and re-transfusion improves hemoglobin levels after coronary artery bypass grafting, but affects coagulative and fibrinolytic systems. Perfusion. 2012;27(4):270-7

22. Zheng J, Du L, Du G, Liu B. Coagulopathy associated with cell salvage transfusion following cerebrovascular surgery. Pak J Med Sci. 2013;29(6):1459-61. 
23. Vymazal T, Filaun M, Horacek M. Impact of retransfusion of blood processed in cell-saver on coagulation versus cardiopulmonary bypass: a prospective observational study using thromboelastography. Biomed Pap Med Fac Univ Palacky Olomouc Czech Repub. 2015;159(1):131-4.
24. Du L, Zheng J, Tang Y. High-sensitivity to heparin associates with cell salvage transfusion in adolescent idiopathic scoliosis patient undergoing posterior spinal fusion. Int J Clin Exp Med. 2014;7(8):2380-2.
Submit your next manuscript to BioMed Central and we will help you at every step:

- We accept pre-submission inquiries

- Our selector tool helps you to find the most relevant journal

- We provide round the clock customer support

- Convenient online submission

- Thorough peer review

- Inclusion in PubMed and all major indexing services

- Maximum visibility for your research

Submit your manuscript at www.biomedcentral.com/submit
(O) Biomed Central 